\title{
The North Carolina AHEC Network
}

\author{
Lynne Siemers
}

"The North Carolina Area Health Education Center (AHEC) Program is a unique partnership between the university health science center and the community ... to improve the geographic distribution of well-trained health professionals and support personnel, and to increase the supply of personnel trained to meet the primary health care needs of the people of North Carolina."

In addition to its goal of training and retraining primary health care personnel and improving the distribution of health manpower, the AHEC program is a voluntary effort to

1. Enhance the professional environment by providing opportunities for continuing education and technical assistance for all health personnel at a regional and local level. 2. Provide training opportunities in community settings for students in allied health, dentistry, medicine, nursing, pharmacy and public health.

3. Avoid duplication of training efforts by a coordinated system of university and community education networks, while enhancing regional training capabilities. ${ }^{2}$

The nine AHECs in the state are linked to a university health sciences center as well as community hospitals, other university campuses, community colleges, technical institutes, and practicing professionals in their respective regions. The program has developed under the leadership of the dean of the School of Medicine at the University of North Carolina in Chapel Hill with the cooperation of other health schools at Chapel Hill (Dentistry, Nursing, Pharmacy, Public Health), the Bowman Gray School of Medicine of Wake Forest University, the Duke University Medical Center, and the East Carolina University Health Science Schools (Medicine, Nursing, Allied Health).

\section{The History of AHEC in North Carolina}

In 1970 the Carnegie Commission on Higher Education issued a report, Higher Education and the Nation's Health. This report came at a time of concern over the shortage of health manpower; the Comprehensive Health Manpower Training Act of 1971 was strongly influenced by the report.

Lynne Siemers is AHEC Liaison Librarian at the Health Sciences Library at the University of North Carolina at Chapel Hill.
One recommendation of the Carnegie Commission called for the creation of area health education centers designed to improve the quality of health training and to overcome the geographic maldistribution of health professionals. ${ }^{3}$

At the same time, the UNC-CH School of Medicine was developing affiliations with community hospitals in the state to provide clinical training for medical students. Funds for this activity were provided by the North Carolina Regional Medical Program, the Duke Endowment, and the North Carolina General Assembly. These activities enabled the university to respond to requests for intent to develop AHEC programs from the Bureau of Health Manpower Education of the Department of Health, Education, and Welfare. Monies for these AHECs had been authorized in the 1971 Comprehensive Health Manpower Training Act.

In 1972, HEW awarded the UNC-CH School of Medicine a contract for $\$ 8.5$ million to develop three AHECs. This was one of the original eleven contracts in the country. The school received an additional $\$ 1$ million for the projects from state funds and from six community hospitals. In 1974 the North Carolina General Assembly appropriated $\$ 28.2$ million to expand the AHEC program into a statewide network with nine regional centers. Each AHEC was to include a library and audiovisual resource center.

\section{The Library and Information Services Network}

The North Carolina AHEC program marked its ten-year anniversary in 1983. An integral part of the program-some say its most visible component-has always been the library and information services network. The network itself is a statewide resource, providing access for health professionals not only to the resources of each of the thirteen present AHEC libraries but also to the health science center libraries. In addition, each AHEC library has developed its collections and services in response to the unique needs of the region's health professionals. Networking is a key component among the objectives which the libraries defined for themselves in the 1981 Standards: 
1. To provide information services to the AHEC region from the AHEC center by developing a core collection of books, audiovisual materials, and journals within the region and by providing access to the resource libraries of North Carolina and the national biomedical communication networks. 2. To develop library collections in health care facilities located in the AHEC region.

3. To provide access to audiovisual equipment and production services in support of educational activities of the AHEC region through referral or on-site facilities.

4. To disseminate information concerning AHEC and especially library learning resource center resources and services.

5. To make all types of information more available by a network of shared resources with public libraries and libraries of other health agencies, community colleges, and technical institutes. ${ }^{4}$

Perhaps one of the most telling indications of the growth of the network of AHEC libraries is the increase in professional personnel. The first AHEC librarian was hired in 1974. Ten years later, there are 17 librarians employed throughout the state.

Having realized early on the benefits of cooperation and networking, the AHEC libraries and librarians have continued to add to the list of accomplishments of the network. To date this ranges from the fifth edition of the Union List of Audiovisuals to on-line demonstrations at state meetings of health professionals.

\section{Network Products and Services}

The North Carolina AHECAudiovisual Union List is published annually. The 1983-84 edition, available in either microfiche or paper copy, lists over eight thousand unique audiovisual programs. Holdings include the four academic resource libraries and the nine AHEC libraries. Microfiche copies are distributed free to all North Carolina hospitals. Other libraries and agencies may purchase the list from the Central AHEC Office.

Other products of the AHEC network include a monthly newsletter, an annual directory of personnel, and the 1981 NC AHEC Library/LRC Standards. These standards reflect the emphasis on local development which is apparent throughout the system: “... a major strength of the AHEC program lies in the autonomy granted each regional center; [thus,] no attempt has been made to give numerical quotas in the standards statements. Rather, the focus is on stating the scope, level, and quality of service recommended; [the] guidelines are intended to assist in attaining ... standards. This is both an assessment and planning tool that will enable AHEC directors and staff to develop services cooperatively to address regional needs. ${ }^{\mathrm{5}}$

Because all AHEC libraries have access to the on-line databases of both Bibliographic Retrieval
Services, Inc., and the National Library of Medicine, it has become almost routine to plan the educational demonstrations of these on-line services at the annual meetings of physicians, nurses, pharmacists, dentists, physicians' assistants, hospital administrators, and public health personnel. A follow-up study is planned to determine what effect participation in these demonstrations has on the further use of library and information services by these health professionals.

\section{Regional Differences}

While the primary focus so far has been on the cooperative activities of the network, it is equally important to examine the difference between library and information services in each AHEC (see Figure 1). It is here that the "regional autonomy" becomes clear, since each has been developed in response to the needs of the region; in fact, some of the strengths of the network come from the local diversity represented by each AHEC.

Mountain AHEC (Asheville) serves as the library for both Memorial Mission and St. Joseph's hospitals. Located in a bridge between the two institutions, MAHEC also offers the services of its combined information/media services department to the area's health professionals and students. It is the only one of the AHECs so structured.

The seventeen counties which comprise the Northwest AHEC (Winston-Salem) have been organized into four subregions. The library and information services in each of these subregions is centered around a multitype, cost-sharing consortium. This concept was first implemented in the Hickory area with the formation of the UNIFOUR consortium. ${ }^{6}$ Boone, Winston-Salem, and Salisbury are the headquarters sites of the other consortia. In addition to hospital libraries, community colleges, mental health centers, schools of nursing, local health departments, and state institutions are members of these consortia. Services are delivered by librarians on a regular circuit to each member institution.

Development of local consortia, but on a voluntary basis, has been the route taken by the Greensboro AHEC. The Rockingham County Health Information Consortium and Randolph County Health Information Consortium, both multitype consortia, received National Library of Medicine grant funds to aid in the development of resources in individual libraries and for the support of intraconsortium activities. With the expiration of the grant funds at the end of 1983 , the members of the Rockingham Consortium have agreed to share the salary for a part-time coordinator. Another volun- 
tary consortium in Alamance County is in the organizational stage.

The Library/LRC at the Charlotte AHEC is a result of the 1976 merger of the library resources of Charlotte AHEC and the Mecklenburg County Medical Society. Library and information services in the Charlotte AHEC area as well as those in Wilmington, Eastern (based at the Health Sciences Library of ECU, Greenville) and Area L (Tarboro) are provided through a combination of circuitriding librarians and consultant contacts at community hospitals and local health agencies.

National Library of Medicine grant funds were awarded to support the development of AHECbased consortia in two regions. The Fayetteville AHEC received funds for the Cape Fear Health Sciences Information Consortium, a group of fourteen hospitals, technical institutes, public libraries, state universities, and public health agencies. The journal holdings of the consortium are included in the Cape Fear Library Association's Union List of Serials.

Most recently the Resources for Health Information (ReHI) Consortium received grant funding. The Wake AHEC (Raleigh) serves as the administrator for this consortium of fifteen institutions. Hospitals in Durham and Person counties are also members of the consortium.

\section{Network Coordination and Professional Development}

Technical assistance and consultations are provided to all AHEC libraries by the AHEC liaison librarian and the audiovisual liaison based at the UNC-CH Health Sciences Library. Through a contractual arrangement with the central AHEC office, this academic resource library provides staff and support for these positions.

As the network has evolved over the past ten years, roles played by both the academic health sciences center libraries and the AHEC libraries have changed. The Health Sciences Library at the University of North Carolina at Chapel Hill serves as the primary resource library for Mountain, Greensboro, Area L, Wake, Charlotte, and Wilmington AHECs; Northwest AHEC makes use of the Carpenter Library of the Bowman Gray School of Medicine; FAHEC's ties are to the Duke Medical Center Library; and the outreach library services of Eastern AHEC are based at the Health Sciences Library of East Carolina University in Greenville.

The dependence on the resources of these academic libraries has declined as the AHEC libraries have built their respective collections of resources and established and strengthened ties with libraries within their regions. Indeed, as the AHEC libraries themselves have identified their

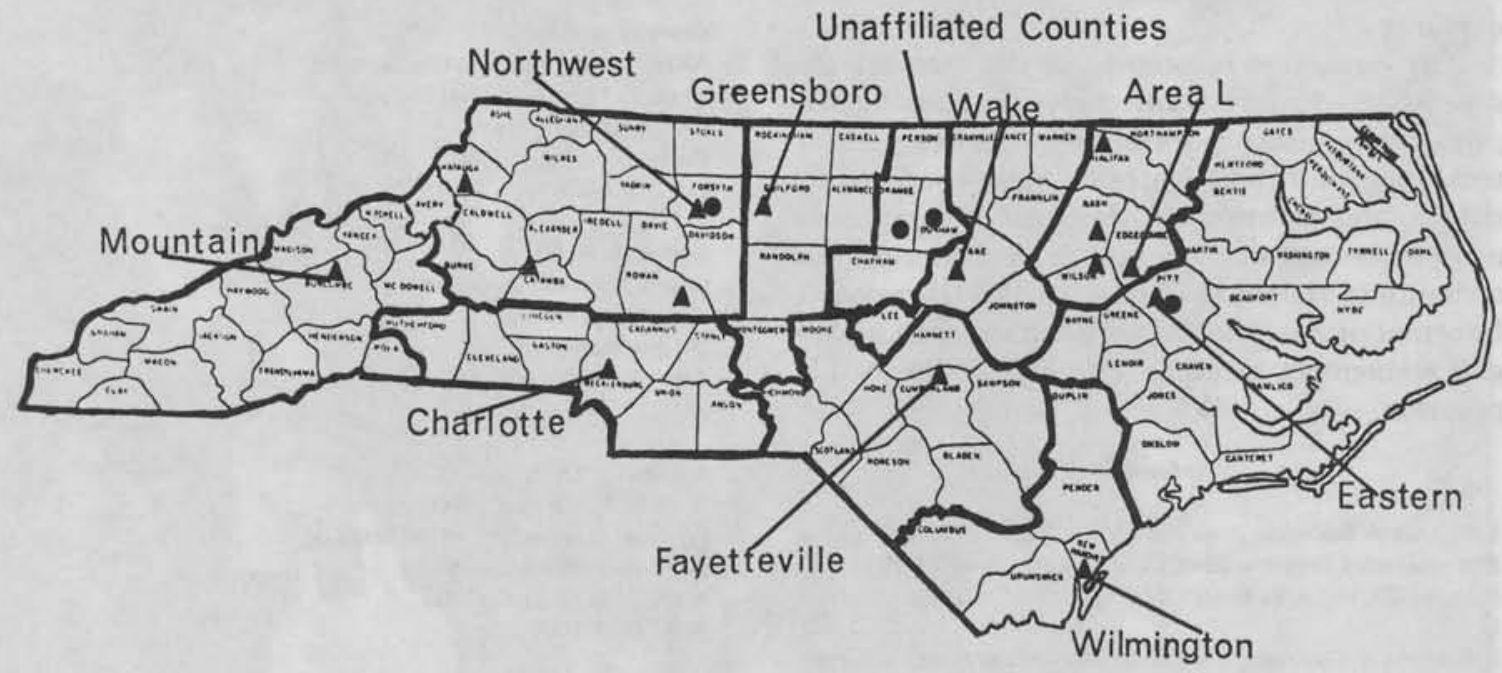

\ AHEC Library/LRC

- University Health Sciences Library 
own resources for each other, inter-AHEC borrowing and lending have increased.

Continuing education, an important component of the AHEC program, has been provided by and for AHEC librarians. In a small hospital or health agency, responsibilities for the daily operation of the library often are assigned to personnel with other unrelated duties. Many seminars are geared for these untrained hospital library managers. Seminars address subjects such as basic reference and technical services, introduction to cataloging, and interlibrary loan services. AHEC librarians have attended such courses as teaching skills for library educators, managerial writing, grantsmanship, and assertiveness training.

\section{Conclusion}

The North Carolina AHEC Program is entering its second decade with a new five year plan for 1985-1990. The Library and Information Services Network has also begun to lay groundwork for the future. In addition to supporting new AHEC programs focused on aging, health promotion/disease prevention, environmental and occupational health, and management education for health professionals, AHEC libraries are planning for the increasing use of technology. IBM XT microcomputers will be installed in 1984 in all AHEC and resource libraries. Planned network use of these machines includes preparation of updates for both the audiovisual and journal union lists, quarterly and annual statistical reports, and demonstrations. Electronic linkages for messages, bulletin boards, and interlibrary loans are also being explored.

By remaining responsive to the increasingly sophisticated information needs of regional health professionals, incorporating appropriate uses of technology for both internal and cooperative efforts, and through maintenance of a commitment to strengthening ties to the local information community, the North Carolina AHEC Library and Information Services Network will remain an integral element in meeting the goals of the AHEC program.

\section{References}

1. The North Carolina Area Health Education Center Program: Recommended Program Plan, July 1, 1980-June 30, 1985 (Chapel Hill, NC: Area Health Education Centers Program, n.d.), i.

2. Rebecca W. Davidson, The Library/Learning Resource Center Network of the North Carolina AHEC Program (Atlanta, GA; Center for Disease Control, 1981), v.

3. Charles E. Odegaard, Area Health Education Centers: the Pioneering Years, 1972-1978 (Berkeley, CA: Carnegie Council on Policy Studies in Higher Education, 1979), viii.
4. North Carolina Area Health Education Centers Library/LRC Standards, 1981 (n.p., 1981), 1.

5. Ibid., introduction.

6. Phyllis Gillikin, et al., "A Self-Supporting Library Service in a Rural Region; A New Look at Hospital Consortia,"

Bulletin of the Medical Library Association 70 (April 1982): 216-223.

\section{Appendix A \\ North Carolina \\ Area Health Education Centers \\ Libraries}

Area L AHEC

Library/Information Services

Health Education Foundation of Eastern North Carolina, Inc. P.O. Drawer 1319

Tarboro, NC 27886

919-823-1353

Charlotte AHEC

Medical Library of Mecklenburg County/Learning Resource

Center of Charlotte AHEC

P.O. Box 32861

Charlotte, NC 28232

704-331-3129

\section{Eastern AHEC}

Outreach Library Services

Health Sciences Library

East Carolina University

Greenville, NC 27834

919-757-2242

\section{Fayetteville AHEC}

Library/Information Services

FAHEC

1601-B Owen Drive

Fayetteville, NC 28304

919-323-1152

\section{Greensboro AHEC}

AHEC Library/Information Services

Moses H. Cone Memorial Hospital

1200 North Elm Street

Greensboro, NC 27420

919-379-4483

\section{Mountain AHEC}

Information and Media Services

Mountain AHEC

501 Biltmore Ave.

Asheville, NC 28801

704-258-0881

Northwest AHEC

Area IV, Northwest AHEC

Bowman Gray School of Medicine

300 South Hawthorne Road

Winston-Salem, NC 27103

919-748-2008

Northwest AHEC Library

Catawba Memorial Hospital

Fairgrove Church Road

Hickory,NC 28601

704-322-0662 
Northwest AHEC Library

Rowan Memorial Hospital

612 Mocksville Ave.

Salisbury, NC 28144

704-638-1081

Northwest AHEC Library

Watauga County Hospital

Deerfield Road

Boone, NC 28607

704-264-2431

\section{Wake AHEC}

Medical Library

Wake County Medical Center

3000 New Bern Ave.

Raleigh,NC 27610

919-755-8529

\section{Wilmington AHEC}

Medical Library

New Hanover Memorial Hospital

2131 S. 17th Street

Wilmington, NC 28402-9990

919-343-0161
University Health Sciences Center Libraries

Coy C. Carpenter Library

Bowman Gray School of Medicine

300 South Hawthorne Road

Winston-Salem, NC 27103

919-748-4691

Medical Center Library

Duke University

Durham, NC 27710

919-684-2011

Health Sciences Library

East Carolina University

Greenville, NC 27834

919-757-2212

Health Sciences Library

University of North Carolina at Chapel Hill

Chapel Hill, NC 27514

919-966-2111

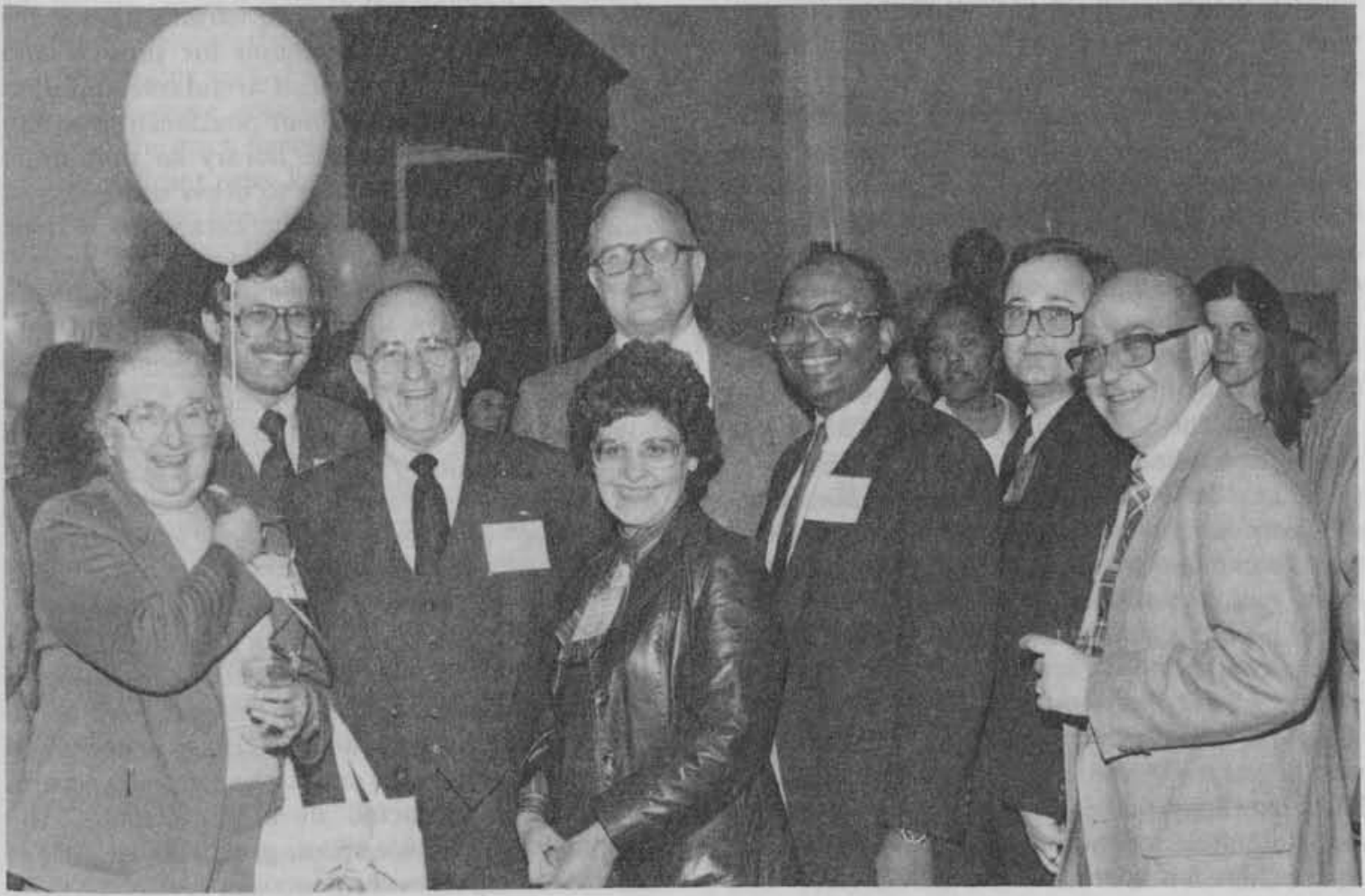

NCLA delegation to ALA Legislative Day in Washington: ( 1 to $r$ ) Louise Boone, Jerry Thrasher, J. A. Killian, William Bridgman, Artemis Kares, Dr. Benjamin Speller, Henry Hall, and Arial Stephens. The delegation visited Congressmen Ike Andrews, Stephen Neal, Tim Valentine, Robin Britt, and Jim Martin. 